\title{
Correction to: The Use of OJIP Fluorescence Transients to Monitor the Effect of Elevated Ozone on Biomass of Canola Plants
}

\author{
Bheki G. Maliba (D) P Prabhu M. Inbaraj • \\ Jacques M. Berner
}

Published online: 22 April 2019

(C) Springer Nature Switzerland AG 2019

\section{Correction to: Water Air Soil Pollut https://doi.org/10.1007/s11270-019-4124-y}

In the original publication's Fig. 1b, the labels J and I, should be placed at approximately $2 \mathrm{~ms}$ and $30 \mathrm{~ms}$ respectively. Also, Fig. 3C y-axis title should be written as $\psi_{\text {Eo }} /\left(1-\psi_{\text {Eo }}\right)$. The corrected Figs. 1 and 3 are provided here.

B. G. Maliba · P. M. Inbaraj · J. M. Berner

Unit for Environmental Sciences and Management, North-West University, Potchefstroom, South Africa

B. G. Maliba $(\square)$

Eskom Research, Testing and Development, Cleveland, Johannesburg, South Africa

e-mail: bmaliba@gmail.com

P. M. Inbaraj

Department of Chemistry, School of Basic Sciences, Manipal University Jaipur, Jaipur, Rajasthan, India 
a

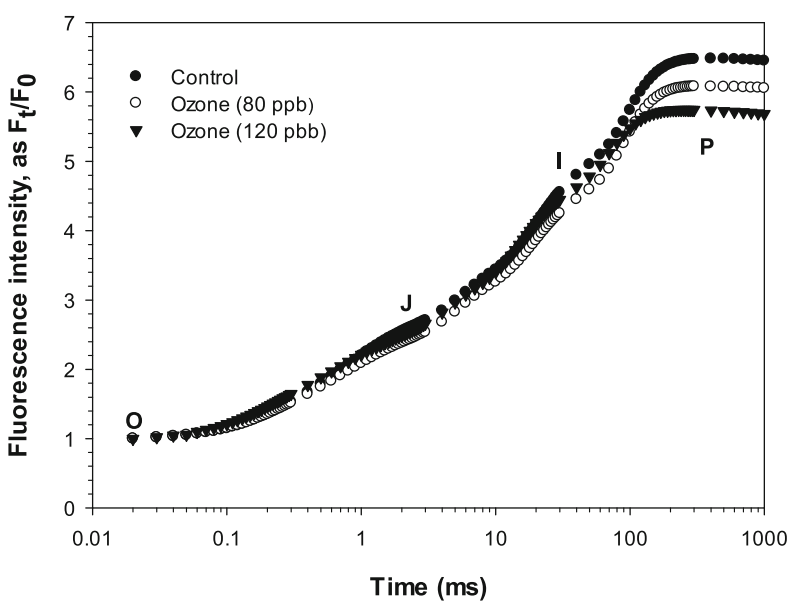

b

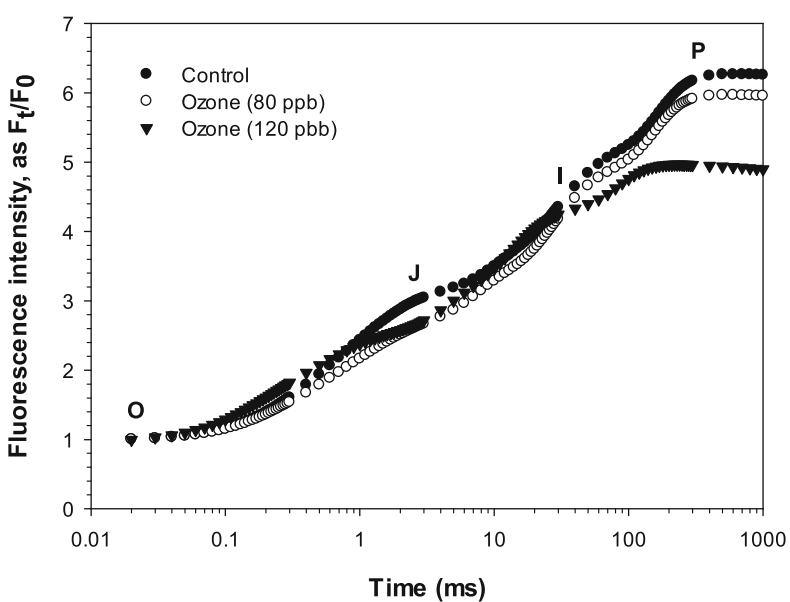

Fig. 1 The average chlorophyll $a$ fluorescence transients OJIP emitted by leaves of canola plants exposed to $\mathrm{O}_{3}$ fumigation ( 80 ppb and $120 \mathrm{ppb}$ ) for 15 days (a) and 30 days (b), along with the transients from non-fumigated plants of the same age (control)
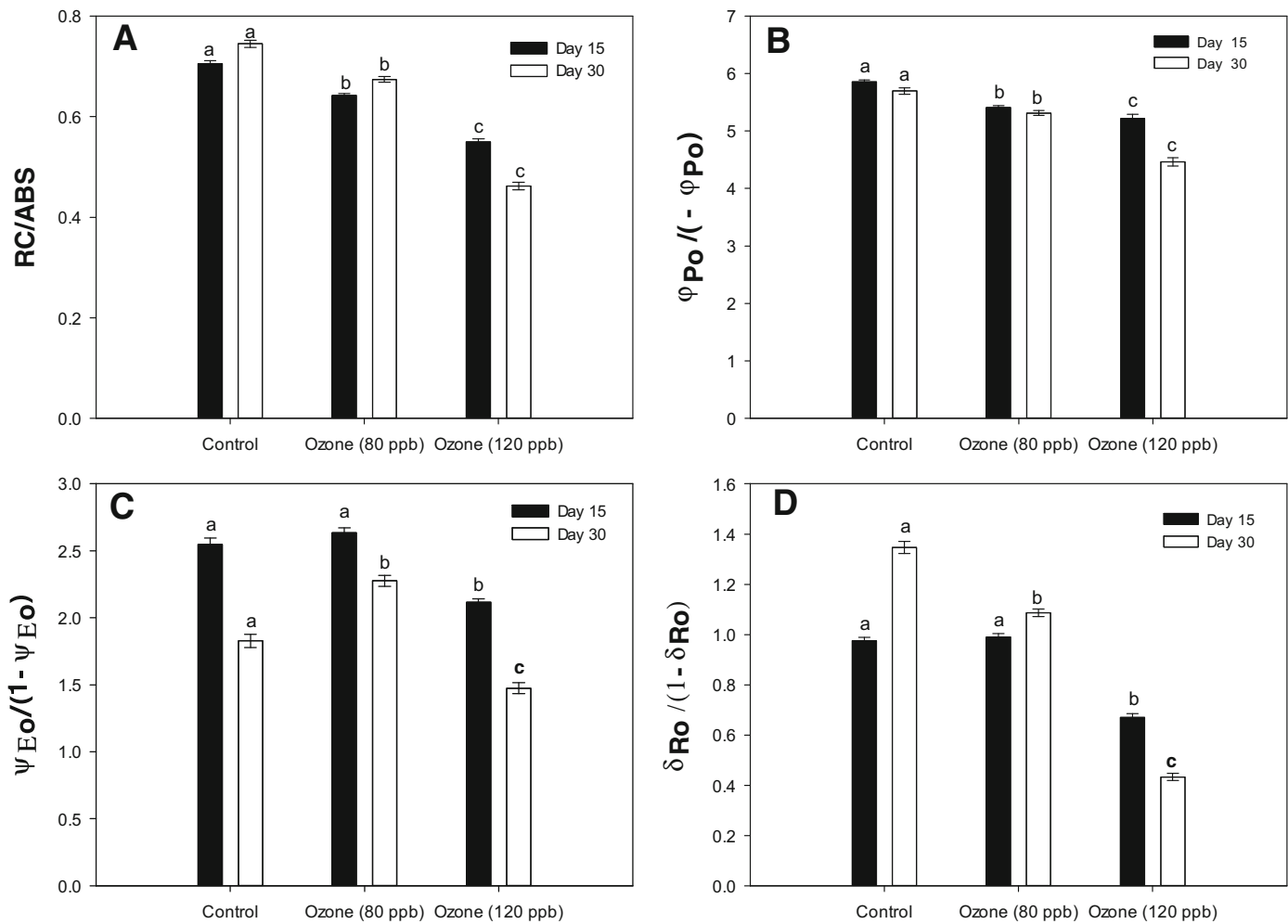

Fig. 3 Average values of the four components [RC/ABS, $\varphi_{\mathrm{Po}} /$ $\left.\left(1-\varphi_{\mathrm{Po}}\right), \psi_{\mathrm{Eo}} /\left(1-\psi_{\mathrm{Eo}}\right), \delta_{\mathrm{Ro}} /\left(1-\delta_{\mathrm{Ro}}\right)\right]$ of the performance index $\left(\mathrm{PI}_{\text {total }}\right)$ of canola plants exposed to $\mathrm{O}_{3}$ fumigation (80 $\mathrm{ppb}$ and $120 \mathrm{ppb}$ ) for 15 and 30 days and of non-fumigated

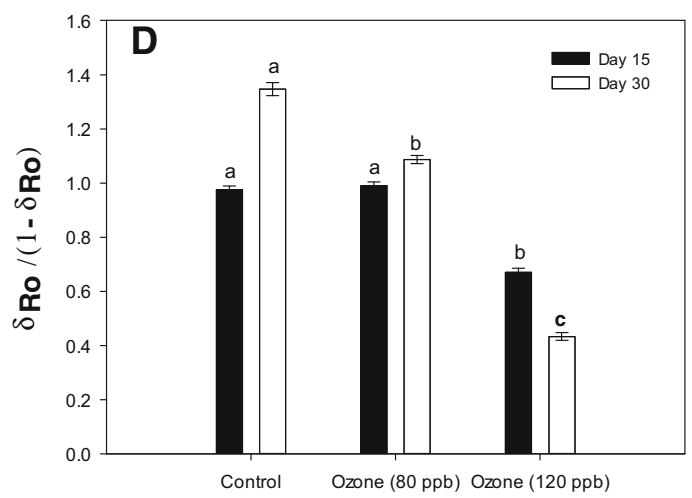

plants of the same age. Bars show standard error. For the same day, different letters above the columns indicate statistically significant differences $(p<0.05)$

Publisher's Note Springer Nature remains neutral with regard to jurisdictional claims in published maps and institutional affiliations. 